\title{
Domain specificity in the primate prefrontal cortex
}

\author{
LIZABETH M. ROMANSKI \\ University of Rochester, Rochester, New York
}

\begin{abstract}
Experimental studies in nonhuman primates and functional imaging studies in humans have underlined the critical role played by the prefrontal cortex (PFC) in working memory. However, the precise organization of the frontal lobes with respect to the different types of information operated upon is a point of controversy, and several models of functional organizations have been proposed. One model, developed by Goldman-Rakic and colleagues, postulates a modular organization of working memory based on the type of information processing (the domain specificity hypothesis). Evidence to date has focused on the encoding of the locations of visual objects by the dorsolateral PFC, whereas the ventrolateral PFC is suggested to be involved in processing the features and identity of objects. In this model, domain should refer to any sensory modality that registers information relevant to that domain-for example, there would be visual and auditory input to a spatial information processing region and a feature analysis system. In support of this model, recent studies have described pathways from the posterior and anterior auditory association cortex that target dorsolateral spatial-processing regions and ventrolateral object-processing regions, respectively. In addition, physiological recordings from the ventrolateral PFC indicate that some cells in this region are responsive to the features of complex sounds. Finally, recordings in adjacent ventrolateral prefrontal regions have shown that the features of somatosensory stimuli can be discriminated and encoded by ventrolateral prefrontal neurons. These discoveries argue that two domains, differing with respect to the type of information being processed, and not with respect to the sensory modality of the information, are specifically localized to discrete regions of the PFC and embody the domain specificity hypothesis, first proposed by Patricia GoldmanRakic.
\end{abstract}

The suggestion that brain regions can be dissociated by function dates back more than a century to the idea of functional localization articulated in works by Paul Broca (1861), David Ferrier (1876), and others. A number of researchers, including Fulton (1950), Mishkin (1964), Fuster (1989), and Petrides (Petrides, Alivisatos, \& Frey, 2002) have argued for a functional dissociation of frontal lobe regions, but none so elegantly as Goldman-Rakic (1987, 1996a, 1996b). Goldman-Rakic brought evidence from multiple subfields of neuroscience together and emphasized the differential contribution of distinct parallel networks in the service of working memory. Her theory of prefrontal organization, the domain specificity hypothesis, can be summarized succinctly: "Experimental studies in nonhuman primates indicate that there may be multiple working memory domains, localized in a different anatomical subdivision of the prefrontal cortex of

This research was supported by National Institute for Deafness and Communication Disorders Grant DC 04845. The author thanks F. A. W. Wilson and M. V. Chafee for their critical comments. Special thanks to S. Mark Williams and Pyramis Studios for their assistance with the illustrations. Correspondence concerning this article should be sent to L. M. Romanski, Department of Neurobiology and Anatomy, University of Rochester, 601 Elmwood Avenue, Box 603, Rochester, NY 14642 (e-mail: liz_romanski@urmc.rochester.edu). both human and nonhuman primates, and each having its own specialized processing and content-specific storage mechanisms" (Goldman-Rakic, 1996b, p. 13473). This hypothesis leans heavily on the notion that visual information could be segregated into dorsal and ventral visual streams (Ungerleider \& Mishkin, 1982). Goldman-Rakic was not the first to propose that dorsal and ventral streams of the visual system might continue forward into the frontal lobes in order to define separate functional domains. This was argued by Mishkin and colleagues in an earlier study (Macko et al., 1982). These investigators identified an occipito-temporo-prefrontal pathway for object vision and an occipito-parieto-prefrontal pathway for spatial vision with the 2-deoxyglucose imaging technique, building on the theory of dorsal and ventral visual streams (Ungerleider \& Mishkin, 1982). Since that time, numerous physiological, anatomical, and behavioral studies have focused on the role of the prefrontal cortices (PFCs) in higher cognitive functions. Here, we will review the evidence for a stimulus-related dissociation between the dorsolateral PFC (DLPFC) and the ventrolateral PFC (VLPFC) in the primate brain, highlighting the contribution of Goldman-Rakic and her associates. Since the case for DLPFC involvement in spatial working memory has been discussed at length, we will focus on evidence that supports a VLPFC region specialized for the processing of object features or object-related working memory. 


\section{Evidence for Dorsolateral Spatial Processing in Nonhuman Primates}

Most of what we know about prefrontal neurophysiological activity derives from recordings performed with nonhuman primates. Nonhuman primates have a highly developed frontal lobe, including the region known as the PFC. The PFC includes the cortical region anterior to the superior and inferior arcuate sulci. Many of the electrophysiological recording studies in nonhuman primates have focused on the visuospatial properties of DLPFC neurons. The behavioral tasks performed by monkeys during the frontal lobe recordings included variations of spatial working memory tasks. One task that has been used frequently is the oculomotor delayed response (ODR) task, in which animals are trained to make a saccade to a remembered peripheral location after a specified delay. Early studies of dorsolateral prefrontal neurons revealed that prefrontal neurons exhibit neuronal firing bridging the stimulus-absent delay period of the ODR (Kojima \& Goldman-Rakic, 1984; for a review, see Fuster, 1997). This delay period activity is thought to make up the neuronal mechanism of working memory. Delay period firing is directly correlated with discrete locations in space, so that some cells have memory fields for these locations (Goldman-Rakic, 1996a). Goldman-Rakic and her colleagues showed that populations of prefrontal neurons are tuned to a single preferred location and that their level of activity decreases as a function of the distance between a given location and the one stored in working memory (Funahashi, Bruce, \& Goldman-Rakic, 1989). When small lesions are made within the DLPFC, very specific mnemonic scotomas, or memory deficits for particular hemifields or visual field locations, can be demonstrated (Funahashi, Bruce, \& Goldman-Rakic, 1993). The spatial storage mechanism that DLPFC neurons use during working memory tasks has been further investigated, and neurons coding the locations either of past stimuli (Chafee \& Goldman-Rakic 1998; Constantinidis, Franowicz, \& Goldman-Rakic, 2001; Funahashi et al., 1993) or of future movements (Funahashi et al., 1993) have been observed.

Neurons capable of holding specific visuospatial coordinates on line have been observed predominantly within the DLPFC, which receives a direct and robust projection from the posterior parietal cortex (GoldmanRakic, 1999). In particular, areas 8a and caudal 46 receive a dense projection from parietal areas $7 \mathrm{a}$ and $7 \mathrm{ip}$ (Cavada \& Goldman-Rakic, 1989). These areas are, in turn, connected to a number of cortical and subcortical regions thought to make up the spatial working memory circuit (Selemon \& Goldman-Rakic, 1988). It is thought that reverberant activity through the parietal-prefrontal circuit may account for the sustained neuronal firing that characterizes the delay period observed in spatial working memory tasks (Chafee \& Goldman-Rakic, 1998; Selemon \& Goldman-Rakic, 1988).

\section{Evidence for Ventrolateral Object/Form Processing in Nonhuman Primates}

In 1993, Wilson, Ó Scalaidhe, and Goldman-Rakic published a groundbreaking study revealing a physiological dissociation between the DLPFC and the VLPFC. In this study, the authors showed that DLPFC cells responded in a spatial working memory task (ODR), with single cells exhibiting selective cue and delay activity for discrete eccentric locations. In the same animals, it was shown that electrode penetrations into VLPFC regions that included the expanse of the inferior convexity (areas 12 lateral, 12 orbital, and 45) revealed neuronal responses that were selectively active during the presentation of pictures of objects and faces. These VLPFC cells did not respond in the spatial working memory task but did respond when pictures of objects or faces were shown during a simple fixation task or as part of a conditional delayed response task. VLPFC neurons had large receptive fields that included the fovea, in contrast to DLPFC neurons, which had eccentric receptive fields that did not always include the fovea. Importantly, when the receptive fields of DLPFC neurons were tested, stimuli were presented at $13^{\circ}$ eccentricity, which is outside of the area centralis. VLPFC neurons responded better to complex visual stimuli presented foveally, whereas DLPFC neurons showed the typical location-selective spatial responses. Recordings in this study covered a wide region of the DLPFC and the VLPFC to reveal this gradient of information-processing specificity between the DLPFC and the VLPFC. Moreover, injections of tracers into the VLPFC resulted in labeling of neurons in the inferotemporal cortex, which is itself involved in object and face processing (Bates, Wilson, Ó Scalaidhe, \& GoldmanRakic, 1994). Further evidence of the role of the VLPFC in feature processing was offered in later publications, which demonstrated face-responsive cells in select regions of the VLPFC (Ó Scalaidhe, Wilson, \& GoldmanRakic, 1997, 1999). Previous recordings in the VLPFC have shown that cells in this region are responsive to simple and complex visual stimuli presented at the fovea (Pigarev, Rizzolatti, \& Scandolara, 1979; Rosenkilde, Bauer, \& Fuster, 1981; Suzuki \& Azuma, 1983).

Although these studies were the first to demonstrate an electrophysiological dissociation between the DLPFC and the VLPFC, they were not the first to suggest a functional difference. A number of lesion studies have focused on the role of the DLPFC in spatial memory (for a review, see Goldman-Rakic, 1987; Levy \& Goldman-Rakic, 2000) and the potential role of inferior prefrontal areas for nonspatial processing. Two early studies (Mishkin \& Manning, 1978; Passingham, 1975) showed that lesions of the VLPFC in nonhuman primates interfere with the processing of nonspatial information, including color and form. Inferior prefrontal lesions had a severe and lasting impairment on the performance of three nonspatial tasks, whereas principal sulcus lesions had only a 
transient effect (Mishkin \& Manning, 1978). Passingham suggested a dissociation between the DLPFC and the VLPFC in their contribution to delayed color matching as a result of the impairment found in their study of VLPFC lesions. In subsequent studies, Passingham and colleagues have persuasively argued against a working memory role for the VLPFC, but the possibility of a contribution to object-related processing has remained (Passingham, Toni, \& Rushworth, 2000; Rushworth, Nixon, Eacott, \& Passingham, 1997).

Anatomists also have noted the difference between the DLPFC and the VLPFC (see Figure 1). For example, Barbas (1988) noted that "the basoventral prefrontal cortices are connected with ventral visual areas implicated in pattern recognition and discrimination, whereas the mediodorsal cortices are connected with medial and dorsolateral occipital and parietal areas associated with visuospatial functions." This dissociation was echoed in a number of early connectional studies (Barbas \& Mesulam, 1981; Barbas \& Pandya, 1989; Chavis \& Pandya, 1976). Goldman-Rakic and colleagues dissected the afferent/efferent DLPFC network and postulated these connections as the underlying structure of spatial working memory (Cavada \& Goldman-Rakic, 1989; Selemon \& Goldman-Rakic, 1988). The connections of the VLPFC with ventral visual stream regions such as the inferotemporal cortex were also noted in some of these early anatomical studies (Barbas, 1988, 1992, 1993; Barbas \&

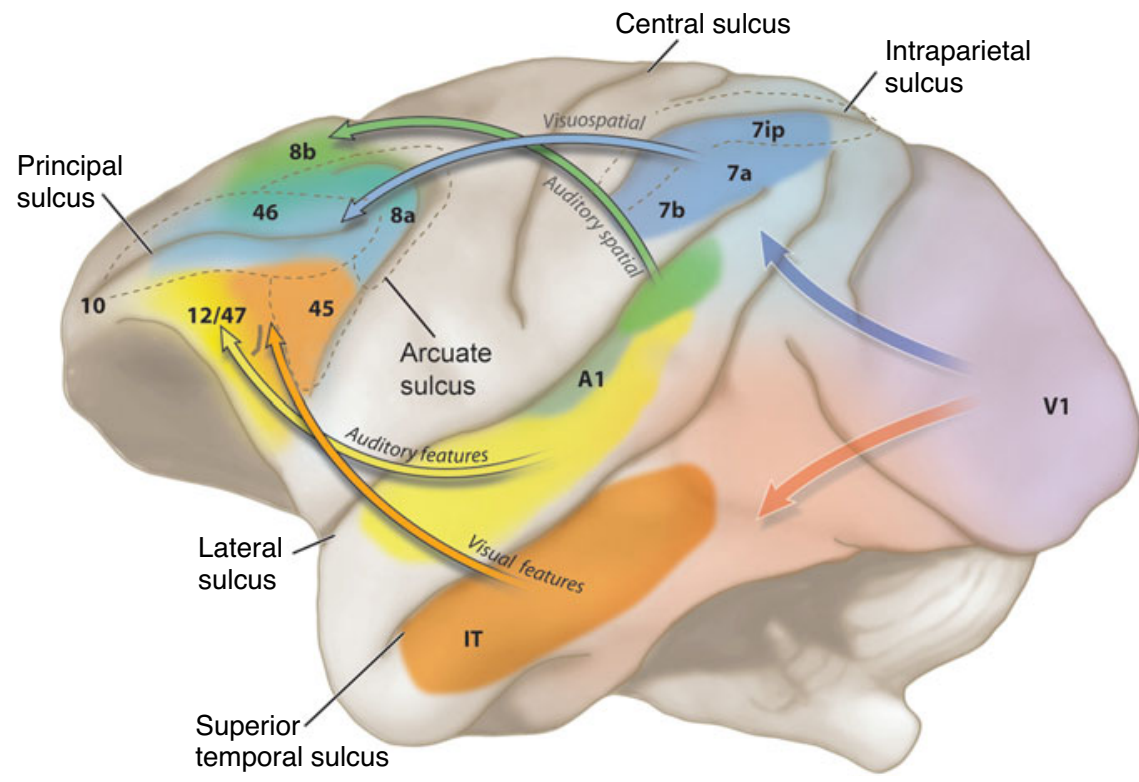

Figure 1. Diagram of the macaque brain indicating the sensory association cortical afferents that innervate the primate prefrontal cortex (PFC) and support the domain specificity hypothesis. The PFC receives information about the spatial location of objects from both visual (blue) and auditory (green) cortices that overlaps within the dorsolateral PFC including areas 46, 8a, and $8 \mathrm{~b}$. Visuospatial information from posterior parietal cortex areas 7ip, $7 \mathrm{a}$, and $7 \mathrm{~b}$ (blue) reaches the principal sulcus areas 46 and $8 \mathrm{a}$ (also in blue), where neurons have been recorded that respond to remembering the spatial locations of objects. Auditoryspatial information from caudal regions of the superior temporal gyrus (green) innervates the caudal and dorsal PFC, including areas 46 dorsal, 8a, and $8 \mathrm{~b}$ (shown in green and greenblue). Auditory neurons in these caudal and dorsal prefrontal areas have been shown to respond to the localization of auditory spatial targets. Object-related processing is believed to occur in the ventrolateral PFC (VLPFC) that receives projections from both visual (orange) and auditory (yellow) cortical processing regions. The inferotemporal cortex, which is involved in object and face processing, projects to prefrontal areas 45, 12 lateral, and 12 orbital. Neurons have been found in the VLPFC that respond to the presentation of faces and objects in perceptual and memory tasks. Auditory association regions of the belt, parabelt, rostral superior temporal region, and cortex in the dorsal bank of the superior temporal sulcus (shown in yellow on the superior temporal gyrus) have all been shown to project to $\mathrm{PFC}$ areas 12 lateral and 12 orbital (yellow). Neurons in these VLPFC regions have recently been shown to respond to complex sounds, including vocalizations. The small sulcus known as the inferior frontal sulcus, or the inferior prefrontal dimple (Paxinos, Huang, \& Toga, 2000), is shown as a small line separating areas $12 / 47$ and 45 . Cytoarchitecture and nomenclature are based on Preuss and Goldman-Rakic (1991). Schematic adapted, with permission, from "Patricia Goldman-Rakic: A Remembrance," by A. Arnsten, 2003, Neuron, 40, p. 467. Copyright 2003 by Elsevier. 
Mesulam, 1985; Chavis \& Pandya, 1976; Jacobson \& Trojanowski, 1977; Pandya, Hallett, \& Kmukherjee, 1969; Petrides \& Pandya, 1988). However, the specific connectivity of VLPFC areas 12 and 45, which had been shown to contain object- and face-selective neurons (Ó Scalaidhe et al., 1997, 1999; Wilson et al., 1993) with inferotemporal areas TE and TEO was specifically documented in Bates et al. (1994) and in Webster, Bachevalier, and Ungerleider (1994). Comparison of TE and TEO connectivity in these studies revealed a number of important differences, including the finding that area TE projections to the VLPFC included orbitofrontal areas 11,12 , and 13 .

Dissociation of vision into two distinct streams has engendered controversy, and the continuation of these separate streams into the frontal lobes has encountered particular opposition. Opponents to Goldman-Rakic's notion that the frontal lobe is composed of domains, separated according to the information they process in the service of working memory have argued that the DLPFC and the VLPFC cannot be dissociated according to the type of information processed. Investigators have instead proposed that these regions differ with regard to the level of information processing (Petrides et al., 2002) and/or the rule or manner in which information is processed (Miller \& Cohen, 2001; Passingham et al., 2000; Rushworth et al., 1997).

In contrast to the dissociable what and where domains of the PFC suggested by Wilson et al. (1993), Miller and colleagues (Rao, Rainer, \& Miller, 1997) focused on the unique, integrative abilities of the PFC. In this study, Rao et al. recorded from neurons near the principal sulcus while nonhuman primates performed a delayed response task that required the animals to remember, conjointly, the identity and the location of a visual cue. Their recordings indicated that although some neurons showed object-tuned or location-tuned delay activity, more than half (in fact, $52 \%$ ) were jointly active during both delay periods. It is worth noting that the stimuli in Rao et al. were not presented as far in the periphery as those Wilson et al. used in demonstrating a distinction between the DLPFC and the VLPFC. In Wilson et al., stimuli were presented at $13^{\circ}$ eccentricity, and in Rao et al., the stimuli (which measured $2^{\circ} \times 2^{\circ}$ ) were presented at $4^{\circ}$ eccentricity, although they were described as being "extrafoveal" (Rao et al., 1997). This study emphasized the importance of task demands in determining the function of prefrontal cells. The potential role of inter-prefrontal connections has been suggested to support the integration of what and where information in these prefrontal neurons (Rao et al., 1997).

In later recording studies, Miller and colleagues further examined stimulus- and process-related activity of lateral PFC neurons in monkeys. These studies have, in general, revealed the importance of context- or rule-based learning for prefrontal function in a non-domain-specific manner. Nonetheless, some support for dissociations of DLPFC and VLPFC functions is evident in these studies. In Asaad, Rainer, and Miller (1998) there was a bias for object-selective cells to be represented more ventrally in the recordings in one animal, although this did not reach statistical significance in the reported sample (Asaad et al., 1998). An additional study examined the memory fields in the lateral frontal cortex when monkeys remembered the identity and location of an object. Examination of the cells that were selectively location tuned indicated that most were located in the posterior part of the recording chamber near the frontal eye fields (FEFs) and might be suggestive of a functional localization, at least for stimulus location (Rainer, Asaad, \& Miller, 1998; discussed in Smith \& Jonides, 1999). Other investigations have supported Goldman-Rakic's dissociation of object and location information in the PFC. For example, Hoshi, Shima, and Tanji (2000) examined the spatial distribution of location-selective and shapeselective neurons during cue, delay, and response periods and found more location-selective neurons in the posterior part of the lateral PFC, whereas more shape-selective neurons were found in the anterior part. Ninokura, Mushiake, and Tanji (2003) found that cells that responded selectively to the physical properties (color and shape) of objects were localized to the VLPFC and cells for which activity was selective for the numerical position (rank order) of objects were confined to the DLPFC.

\section{Sources of Discrepancy Across Studies}

There are a number of potential reasons for the disparity in the electrophysiological PFC data from the DLPFC and the VLPFC in nonhuman primates. One of the most important differences is the recording location across the different studies. The region encompassed by the term $V L P F C$ is large and includes at least three cytoarchitectonically diverse regions (Preuss \& GoldmanRakic, 1991). Differences in the recording locations among investigators could account for the disparity in VLPFC activity reported. It is possible that the objectand face-selective cells encountered by Goldman-Rakic (1996a), Rosenkilde et al. (1981), Hoshi et al. (2000), and others may be localized to a more ventral region of the VLPFC than those in other physiological studies. The recordings of Wilson et al. (1993) and Ó Scalaidhe et al. (1997, 1999) were formerly identified as occurring in the inferior convexity of the macaque monkey. The face cells were often described as being located near a small inferior prefrontal sulcus (Ó Scalaidhe et al., 1997, 1999), called the inferior prefrontal dimple by Paxinos, Huang, \& Toga (2000) and the inferior frontal sulcus by others. In Rhesus macaques, this landmark is located ventrally on the PFC surface and is distant from the principal sulcus. It has rarely been noted in other physiological investigations. Thus, it is possible that the lack of object-selective cells in some recordings of the VLPFC could simply be due to the fact that recordings were not located ventrally enough to reveal them. Not all the studies relied on histological reconstructions in order to confirm this. Furthermore, some of the cells recorded in Wilson et al. (1993) and Ó Scalaidhe et al. (1997, 1999) were located in area 12 orbital, traditionally considered 
part of the inferior convexity but also referred to as part of the orbitofrontal cortex (OFC), which is not always considered in electrophysiological recordings from the VLPFC. Lesion studies have noted the contribution of the orbitofrontal cortex to object recognition and object working memory (Bachevalier \& Mishkin, 1986; Meunier, Bachevalier, \& Mishkin, 1997). Interestingly, a recent study in which the activity of OFC and DLPFC neurons were compared did, in fact, show evidence of a what/where dissociation. In this study, in which nonhuman primates performed a reward preference task, the DLPFC and the OFC were activated by the reward component of the task. However, neurons that encoded the location of the stimuli were observed more commonly in the DLPFC, whereas picture-selective neurons were more commonly observed in the OFC than in the DLPFC (Wallis \& Miller, 2003). A difference in the recording areas may also explain the differences noted in the receptive fields of VLPFC neurons, which were described as foveal by some (Ó Scalaidhe et al., 1997, 1999; Wilson et al., 1993), but not by others. In Rainer et al. (1998), the investigators reported that "only a minority of PF whatand-where neurons were sensitive to foveal stimulation. Indeed, the MFs [memory fields] of most of these neurons were entirely extrafoveal." These extrafoveal receptive fields recorded in the lateral PFC are more typical of the DLPFC than of the VLPFC neurons reported by Wilson et al., which always included the fovea. Use of MRI to visualize the location of ongoing recordings may allow for better comparison of recording regions across different laboratories. Postexperiment histological verification would also clarify this issue.

A second difference among the many studies comparing the DLPFC and the VLPFC is that of task. In an elegant series of studies, Miller and colleagues have demonstrated the importance of task and context in examining the function of the PFC. In one study, the same stimulus, a picture, was presented as a cue in several tasks and, depending on context, indicated different responses. In one example neuron, the response during the cue period of the delayed matching-to-sample task and the conditional response task was drastically different despite the fact that, in both tasks, the same picture was presented during the cue period (Asaad, Rainer, \& Miller, 2000). The context in which the stimulus information was used to formulate a response differed and had a tremendous effect on neuronal activity. Some comparisons of DLPFC and VLPFC neuronal activity have been based on experiments that relied on data acquired during simple fixation tasks. This could have important implications for PFC activity. Thus, the importance of task demands or context cannot be overemphasized and must certainly have an effect on neuronal activity. Proponents of processrelated dissociations in the frontal lobe have argued that particular tasks and levels of processing may activate the DLPFC and the VLPFC differentially. Hence, neurons of the DLPFC are active during tasks of spatial localization and spatial working memory, whereas VLPFC neurons are active during visual conditional response tasks or visual association tasks (Asaad et al., 2000; Gutnikov, Ma, \& Gaffan, 1997; Passingham et al., 2000; Wilson et al., 1993), but not during working memory tasks. Thus, a dissociation of the VLPFC from the DLPFC by process may also be evident (Petrides et al., 2002; Rushworth et al., 1997).

\section{Evidence From Other Modalities}

One of the tenets of Goldman-Rakic's domain specificity hypothesis is that the PFC can be dissociated by the type of information processed independently of stimulus modality. Thus, it should be the case that the DLPFC will process information about where a stimulus is located for visual, auditory, or somatosensory objects. Although most studies have focused on the processing of visual information, there is anatomical and physiological evidence for somatosensory and auditory stimulus processing in the PFC.

A small number of studies have shown activation of the VLPFC by somatosensory stimuli. In the nonhuman primate, recordings were made in the VLPFC while monkeys performed a somatosensory discrimination task (Romo, Brody, Hernandez, \& Lemus, 1999). Neurons were found whose discharge rates varied during the delay period between the two stimuli as a monotonic function of the base stimulus frequency. These cells were localized specifically to the VLPFC (Romo et al., 1999), and the feature-based encoding of these cells supports their role in an object-based ventral stream function. Projections to the VLPFC from somatosensory association cortices have been described (Preuss \& GoldmanRakic, 1989) that could account for these responses. There is also recent neuroimaging evidence, in humans, that the inferior PFC is activated by somatosensory stimulation (Hagen, Zald, Thornton, \& Pardo, 2002).

There is more evidence for the frontal lobe's involvement in higher auditory processing. Recordings in the primate auditory system have suggested that auditory information may diverge into specialized circuits dedicated to the processing of auditory locations and auditory features. These studies have shown that the anterior lateral (AL) belt region, exhibits more selectivity for types of complex sounds, such as vocalizations, whereas the caudal lateral (CL) field has neurons that show greater spatial selectivity (Rauschecker \& Tian, 2000; Tian, Reser, Durham, Kustov, \& Rauschecker, 2001). How these auditory streams innervate the frontal lobes was not clear until recently. Previous anatomical studies relied on injections into anatomically characterized regions of the superior temporal gyrus (STG) without the aid of physiological information. These anatomical studies indicated that a rostro-caudal topography exists such that caudal STG and caudal PFC are reciprocally connected (Barbas, 1992; Chavis \& Pandya, 1976; Pandya \& Kuypers, 1969; Petrides \& Pandya, 1988; Romanski, Bates, \& Goldman-Rakic, 1999; Romanski, Tian, et al., 1999), whereas the rostral STG is reciprocally connected with the rostral principalis (rostral 46 and 10) and orbitofrontal areas (areas 11 and 12; Chavis \& Pandya, 1976; 
Pandya et al., 1969; Pandya \& Kuypers, 1969). Building on this information, investigators traced the frontal connections of physiologically defined lateral belt regions AL, ML, and CL. They found that these connections were topographically organized such that AL projected to the frontal pole (area 10), the rostral principal sulcus (area 46), the inferior convexity (areas $12 \mathrm{vl}$ and 45), and the lateral orbital cortex (areas 11, 12o). In contrast, projections from the CL area were most prominent in the dorsal periarcuate cortex (area 8a, frontal eye fields) and the caudal principal sulcus (area 46; Romanski, Tian, et al., 1999). These highly specific topographical frontaltemporal connections suggest the existence of separate streams of auditory information that target distinct domains of the frontal lobes. One pathway, originating in the CL area, targets the caudal DLPFC; the other pathway, originating in the AL area, targets rostral and ventral prefrontal areas (Romanski, Tian, et al., 1999). Thus, it is possible that the pathways originating from anterior and posterior auditory belt and parabelt cortices are analogous to the what and where streams of the visual system (Figure 1). The recent demonstration of physiological specificity of anterior belt and caudal belt regions (Rauschecker \& Tian, 2000; Tian et al., 2001) adds further evidence to this idea.

Several physiological studies support a role for the caudal PFC in auditory processing. For example, studies have shown that neurons are responsive to simple auditory stimuli in the periarcuate region (Azuma \& Suzuki, 1984; Ito, 1982; Vaadia, Benson, Hienz, \& Goldstein, 1986) and that lesions of the periarcuate cortex can impair auditory discrimination in primates (Gross \& Weiskrantz, 1962; Petrides, 1986). Evidence of a spatial auditory function was demonstrated by investigations showing that neurons in the periarcuate region that respond to auditory stimuli are affected by the location of the sound source (Azuma \& Suzuki, 1984; Kikuchi-Yorioka \& Sawaguchi, 2000; Russo \& Bruce, 1989) and that the auditory responses of these neurons are affected by changes in gaze (Russo \& Bruce, 1989), which is in agreement with the FEF's role in saccadic eye movements to salient targets. Vaadia et al. (1986) noted the increased response of neurons in the periarcuate region when nonhuman primates were engaged in an auditory localization task, as compared with a passive listening task. Furthermore, recordings in monkeys performing spatial delayed response tasks have shown that the DLPFC contains neurons activated by auditory or visual spatial cues (KikuchiYorioka \& Sawaguchi, 2000). Evidence for a DLPFC auditory spatial-processing domain has also been shown in human imaging studies (Bushara et al., 1999; Rama et al., 2004). In one study, maintenance of spatial and nonspatial information preferentially activated dorsal and ventral prefrontal regions, respectively (Rama et al., 2004).

Although the human inferior frontal gyrus (including Broca's area) has been linked with speech and language processes for more than a century, evidence of a VLPFC auditory object region in nonhuman primates is sparse. Responses to acoustic stimuli have only been sporadi- cally noted in the frontal lobes of Old and New World monkeys (Benevento, Fallon, Davis, \& Rezak, 1977; Bodner, Kroger, \& Fuster, 1996; Newman \& Lindsley, 1976; Tanila, Carlson, Linnankoski, \& Kahila, 1993; Tanila, Carlson, Linnankoski, Lindroos, \& Kahila, 1992; Wollberg \& Sela, 1980) without determining a specific locus for auditory prefrontal neurons. Examination of these studies indicates that few of the studies sampled neurons in ventrolateral and orbito-frontal regions with complex auditory stimuli. A recent study, however, has demonstrated a discrete auditory responsive region in the macaque PFC (Romanski \& Goldman-Rakic, 2002). This VLPFC region has neurons that respond to complex acoustic stimuli, including species-specific vocalizations, and lies adjacent to the object-selective region proposed previously (Ó Scalaidhe et al., 1997, 1999; Wilson et al., 1993). Although VLPFC auditory neurons have not been thoroughly tested for directional selectivity, further examination has suggested that they respond to complex stimuli on the basis of acoustic features (Romanski, Averbeck, \& Diltz, 2005). A cluster analysis of auditory prefrontal responses to species-specific vocalizations demonstrated that neurons tend to respond to multiple vocalizations with similar acoustic morphology (Romanski et al., 2005). This is consistent with a role for VLPFC auditory neurons in a ventral auditory processing stream that analyzes the features of auditory objects. The notion of an object-based auditory stream is further supported by human neuroimaging studies (Belin, Zatorre, Lafaille, Ahad, \& Pike, 2000; Binder et al., 2000; Scott, Blank, Rosen, \& Wise, 2000; Zatorre, Bouffard, \& Belin, 2004). Furthermore, the localization of an auditory object processing stream to the VLPFC in the macaque is suggestive of functional similarity between this area and human language-processing regions located in the inferior frontal gyrus (Deacon, 1992; Romanski \& GoldmanRakic, 2002).

It is surprising that auditory responses in the macaque VLPFC have been observed in few electrophysiology studies. In fact, these responses have been noted in only one other study (Benevento et al., 1977). In this study, electrode penetrations were made within the lateral orbital cortex near the ventrolateral regions where auditory responsive neurons were found in Romanski and GoldmanRakic (2002). In that study, Romanski and GoldmanRakic noted that the VLPFC auditory region is small and difficult to find unless anatomical and physiological landmarks are utilized. Thus, it seems that the extreme ventral location (including lateral orbital cortex) of auditory and visual prefrontal neurons has allowed them to elude physiological pursuit. This problem may figure prominently in arguments over the domain specificity hypothesis.

\section{Toward a Synthesis of Process and Information}

The functional domain hypothesis, developed by Goldman-Rakic, is supported by a number of anatomical and electrophysiological studies in animals (Figure 1). Neurons in the DLPFC respond during the cue, delay, 
and response periods of spatial working memory tasks. These same regions of the DLPFC have a robust and reciprocal connection with the posterior parietal cortex, which itself is involved in spatial processing. Neurons of the VLPFC have object-, pattern-, or face-selective activity. The VLPFC receives a direct projection from a number of cortical association areas, including the inferotemporal cortex, which has object- and face-selective neurons. Recent studies have shown that auditory and somatosensory stimuli evoke activity in the PFC in a domain-specific manner. Anatomical studies have shown that caudal auditory belt neurons, which have directional selectivity, innervate DLPFC regions, which themselves have been shown to be active in auditory spatial localization. Neurons in the anterior auditory belt that show vocalization-selective activity project to VLPFC neurons that exhibit feature-based encoding of complex sounds, including vocalizations. Electrophysiological studies have recently demonstrated feature-based processing of somatosensory information in the VLPFC. Arguments against the domain specificity hypothesis have been made in studies that have shown a lack of object-selective processing. However, there is some question as to whether recordings have been made in identical regions of the VLPFC in all the studies. Still other investigations have confirmed object or object-associated processing in the VLPFC but have not substantiated a role for this region in object working memory.

Accumulating evidence from recordings in animals and neuroimaging in humans has emphasized the importance of process-related activity in the PFC. These studies have highlighted how changes in task, rules, or context may alter prefrontal neuronal activity and argue in favor of a prefrontal dissociation according to, or in addition to, process, rather than according to stimulus alone. This may be critical in the human frontal lobe, which has the capacity for a great number of flexible cognitive processes. The degree to which process- or stimulus-related organizational schemes derived from animal physiology and lesion studies can be mapped onto the human frontal lobe remains controversial (GoldmanRakic, 2000). Support for VLPFC involvement in object and face processing is apparent in neuroimaging studies of the human brain (Allison, Puce, Spencer, \& McCarthy, 1999, Courtney, Ungerleider, Keil, \& Haxby, 1996, 1997; Haxby et al., 1996; McCarthy et al., 1996; Puce, Allison, \& McCarthy, 1999). More controversial is whether a human homologue of the nonhuman primate DLPFC spatial-processing region exists. Courtney, Petit, Maisog, Ungerleider, \& Haxby, (1998) have argued that in the human brain, spatial working memory tasks activate a region within the superior frontal sulcus that might be analogous in function to the nonhuman primate DLPFC region. Differences in frontal lobe cytoarchitecture between monkey and man make direct functional comparisons difficult (Rajkowska \& Goldman-Rakic, 1995). No doubt, expansion of the frontal lobes in humans with the advent of language changed the cortical mantle in many ways. More studies are needed to understand the anatomical and functional similarities between the frontal lobes of man and nonhuman primates.

Perhaps a synthesis of stimulus- and process-related activity would afford a better organizational scheme of the PFC. In this manner, types of information (i.e., visuospatial target) may engage particular processes (memoryguided saccades) in some areas (FEFs) or other processes (memory-guided reaching) in neighboring areas (principal sulcus), depending on the task demands or the context. Tasks demanding an association of an object with a particular response would activate the VLPFC, whereas working memory demands or additional processing might involve other areas. More research is needed to determine the essential roles these regions play in particular tasks in the nonhuman primate, as well as how these functional areas map onto anatomical locations in the human brain. A synthesis of the anatomical, physiological, and behavioral methods will allow us to begin to understand the many roles of the PFC in complex cognitive processes. One of the strengths that Goldman-Rakic brought to her extensive work on the brain was her unique ability to synthesize data from a variety of fields and techniques in order to understand the functional organization of the frontal lobes. In 1996, she summed up her views at a meeting quite simply: "structure and function are inextricably related. And I would argue further, that every theory of cortical function should be integrated with knowledge of regional circuitry and physiology" (Goldman-Rakic, 1996a, p. 1445).

\section{REFERENCES}

Allison, T., Puce, A., Spencer, D. D., \& McCarthy, G. (1999). Electrophysiological studies of human face perception: I. Potentials generated in occipitotemporal cortex by face and non-face stimuli. Cerebral Cortex, 9, 415-430.

Arnsten, A. (2003). Patricia Goldman-Rakic: A remembrance. Neuron, 40, 465-470.

ASAAD, W. F., RAINER, G., \& Miller, E. K. (1998). Neural activity in the primate prefrontal cortex during associative learning. Neuron, $\mathbf{2 1}$, 1399-1407.

AsaAd, W. F., Rainer, G., \& Miller, E. K. (2000). Task-specific neural activity in the primate prefrontal cortex. Journal of Neurophysiology, 84, 451-459.

AzUma, M., \& SuzUKI, H. (1984). Properties and distribution of auditory neurons in the dorsolateral prefrontal cortex of the alert monkey. Brain Research, 298, 343-346.

BACHEVAlier, J., \& MishKIN, M. (1986). Visual recognition impairment follows ventromedial but not dorsolateral prefrontal lesions in monkeys. Behavioural Brain Research, 20, 249-261.

BARBAS, H. (1988). Anatomic organization of basoventral and mediodorsal visual recipient prefrontal regions in the rhesus monkey. Journal of Comparative Neurology, 276, 313-342.

BARBAS, H. (1992). Architecture and cortical connections of the prefrontal cortex in the rhesus monkey. Advances in Neurology, 57, 91-115.

BARBAS, H. (1993). Organization of cortical afferent input to orbitofrontal areas in the rhesus monkey. Neuroscience, 56, 841-864.

Barbas, H., \& Mesulam, M. M. (1981). Organization of afferent input to subdivisions of area 8 in the rhesus monkey. Journal of Comparative Neurology, 200, 407-431.

Barbas, H., \& Mesulam, M. M. (1985). Cortical afferent input to the principalis region of the rhesus monkey. Neuroscience, 15, 619-637. Barbas, H., \& Pandya, D. N. (1989). Architecture and intrinsic con- 
nections of the prefrontal cortex in the rhesus monkey. Journal of Comparative Neurology, 286, 353-375.

Bates, J. F., Wilson, F. A. W., Ó Scalaidhe, S. P. O., \& GoldmanRAKIC, P. S. (1994). Area TE connections with inferior prefrontal regions responsive to complex objects and faces. Society for Neuroscience Abstracts, 20, 434.10.

Belin, P., Zatorre, R. J., Lafaille, P., Ahad, P., \& Pike, B. (2000). Voice-selective areas in human auditory cortex. Nature, 403, 309-312.

Benevento, L. A., Fallon, J., Davis, B. J., \& RezaK, M. (1977). Auditory-visual interaction in single cells in the cortex of the superior temporal sulcus and the orbital frontal cortex of the macaque monkey. Experimental Neurology, 57, 849-872.

Binder, J. R., Frost, J. A., HammeKe, T. A., Bellgowan, P. S. F., Springer, J. A., Kaufman, J. N., \& Possing, E. T. (2000). Human temporal lobe activation by speech and nonspeech sounds. Cerebral Cortex, 10, 512-528.

Bodner, M., Kroger, J., \& Fuster, J. M. (1996). Auditory memory cells in dorsolateral prefrontal cortex. NeuroReport, 7, 1905-1908.

BRocA, P. (1861). Remarques sur le siège de la faculté de langage articule suivis d'une observation d'aphemie (perte de la parole). Bulletin de la Societé d'Anatomique, 6, 330-337.

Bushara, K. O., Weeks, R. A., Ishit, K., Catalan, M. J., Tian, B., RausCHeCKER, J. P., \& HALlett, M. (1999). Modality-specific frontal and parietal areas for auditory and visual spatial localization in humans. Nature Neuroscience, 2, 759-766.

Cavada, C., \& Goldman-RaKic, P. S. (1989). Posterior parietal cortex in rhesus monkey: I. Parcellation of areas based on distinctive limbic and sensory corticocortical connections. Journal of Comparative Neurology, 287, 393-421.

CHAFEe, M. V., \& GOLDMAN-RAKIC, P. S. (1998). Matching patterns of activity in primate prefrontal area $8 \mathrm{a}$ and parietal area 7ip neurons during a spatial working memory task. Journal of Neurophysiology, 79, 2919-2940.

CHAVIS, D. A., \& PANDYA, D. N. (1976). Further observations on corticofrontal connections in the rhesus monkey. Brain Research, 117, $369-$ 386.

Constantinidis, C., Franowicz, M. N., \& Goldman-Rakic, P. S. (2001). The sensory nature of mnemonic representation in the primate prefrontal cortex. Nature Neuroscience, 4, 311-316.

Courtney, S. M., Petit, L., Maisog, J. M., Ungerleider, L. G., \& HAXBY, J. V. (1998). An area specialized for spatial working memory in human frontal cortex. Science, 279, 1347-1351.

Courtney, S. M., Ungerleider, L. G., Keil, K., \& Haxby, J. V. (1996). Object and spatial visual working memory activate separate neural systems in human cortex. Cerebral Cortex, 6, 39-49.

Courtney, S. M., Ungerleider, L. G., Keil, K., \& Haxby, J. V. (1997). Transient and sustained activity in a distributed neural system for human working memory. Nature, 386, 608-611.

Deacon, T. W. (1992). Cortical connections of the inferior arcuate sulcus cortex in the macaque brain. Brain Research, 573, 8-26.

FERrIER, D. (1876). The functions of the brain. London: Smith, Elder.

Fulton, J. F. (1950). Functional lobotomy and affective behavior. New York: Norton.

Funahashi, S., Bruce, C. J., \& Goldman-Rakic, P. S. (1989). Mnemonic coding of visual space in the monkey's dorsolateral prefrontal cortex. Journal of Neurophysiology, 61, 331-349.

Funahashi, S., Bruce, C. J., \& Goldman-RaKic, P. S. (1993). Dorsolateral prefrontal lesions and oculomotor delayed-response performance: Evidence for mnemonic "scotomas." Journal of Neuroscience, 13, 1479-1497.

FUSTER, J. M. (1989). The prefrontal cortex: Anatomy, physiology, and neuropsychology of the frontal lobe (2nd ed.). New York: Raven.

Fuster, J. M. (1997). The prefrontal cortex: Anatomy, physiology, and neuropsychology of the frontal lobe (3rd ed.). Philadelphia: LippincottRaven.

Goldman-RAKIC, P. S. (1987). Circuitry of primate prefrontal cortex and regulation of behavior by representational memory. In J. M. Brookhart \& V. B. Mountcastle (Series Eds.) \& F. Plum (Vol. Ed.), Handbook of physiology: Section 1. The nervous system: Vol. V. Higher functions of the brain (pp. 373-418). Bethesda, MD: American Physiological Society.
GolDMAN-RAKIC, P. S. (1996a). The prefrontal landscape: Implications of functional architecture for understanding human mentation and the central executive. Philosophical Transactions of the Royal Society of London: Series $B$, 351, 1445-1453.

GOLDMAN-RAKIC, P. S. (1996b). Regional and cellular fractionation of working memory. Proceedings of the National Academy of Sciences, 93, 13473-13480.

GOLDMAN-RAKIC, P. S. (1999). The "psychic" neuron of the cerebral cortex. In B. Rudy \& P. Seeburg (Eds.), Molecular and functional diversity of ion channels and receptors (Annals of the New York Academy of Sciences, Vol. 868, pp. 13-26). New York: New York Academy of Sciences.

GoLDMAN-RAKIC, P. S. (2000). Localization of function all over again. NeuroImage, 11, 451-457.

Gross, C. G., \& WEISKRANTz, L. (1962). Evidence for dissociation of impairment on auditory discrimination and delayed response following lateral frontal lesions in monkeys. Experimental Neurology, $\mathbf{5}$, 453-476.

Gutnikov, S. A., Ma, Y. Y., \& Gaffan, D. (1997). Temporo-frontal disconnection impairs visual-visual paired association learning but not configural learning in Macaca monkeys. European Journal of Neuroscience, 9, 1524-1529.

Hagen, M. C., ZALD, D. H., Thornton, T. A., \& PARdo, J. V. (2002). Somatosensory processing in the human inferior prefrontal cortex. Journal of Neurophysiology, 88, 1400-1406.

HaXby, J. V., Ungerleider, L. G., Horwitz, B., Maisog, J. M., RAPOPORT, S. I., \& GRADY, C. L. (1996). Face encoding and recognition in the human brain. Proceedings of the National Academy of Sciences, 93, 922-927.

Hoshi, E., SHIMA, K., \& TANJI, J. (2000). Neuronal activity in the primate prefrontal cortex in the process of motor selection based on two behavioral rules. Journal of Neurophysiology, 83, 2355-2373.

ITo, S. I. (1982). Prefrontal unit activity of macaque monkeys during auditory and visual reaction time tasks. Brain Research, 247, 39-47.

JaCobson, S., \& TrojanowsKi, J. Q. (1977). Prefrontal granular cortex of the rhesus monkey: I. Intrahemispheric cortical afferents. Brain Research, 132, 209-233.

KIKUCHI-YoRIOKA, Y., \& SAWAgUCHI, T. (2000). Parallel visuospatial and audiospatial working memory processes in the monkey dorsolateral prefrontal cortex. Nature Neuroscience, 3, 1075-1076.

KoJIMA, S., \& Goldman-RAKIC, P. S. (1984). Functional analysis of spatially discriminative neurons in prefrontal cortex of rhesus monkey. Brain Research, 291, 229-240.

LEVY, R., \& GoLDMAN-RAKIC, P. S. (2000). Segregation of working memory functions within the dorsolateral prefrontal cortex. Experimental Brain Research, 133, 23-32.

Macko, K. A., Jarvis, C. D., Kennedy, C., Miyaoka, M., ShinoHARA, M., SoKoloff, L., \& Mishrin, M. (1982). Mapping the primate visual system with ${ }^{2-14}$ C-deoxyglucose. Science, 218, 394-397.

McCarthy, G., Puce, A., Constable, R. T., Krystal, J. H., Gore, J. C., \& GoldMAN-RAKIC, P. (1996). Activation of human prefrontal cortex during spatial and nonspatial working memory tasks measured by functional MRI. Cerebral Cortex, 6, 600-611.

Meunier, M., Bachevalier, J., \& Mishkin, M. (1997). Effects of orbital frontal and anterior cingulate lesions on object and spatial memory in rhesus monkeys. Neuropsychologia, 35, 999-1015.

Miller, E. K., \& CoHEN, J. D. (2001). An integrative theory of prefrontal cortex function. Annual Review of Neuroscience, 24, 167-202.

MishKin, M. (1964). Perseveration of central sets after frontal lesions in monkeys. In J. K. Warren \& K. Akert (Eds.), The frontal granular cortex and behavior (pp. 219-241). New York: McGraw-Hill.

Mishkin, M., \& MANNING, F. J. (1978). Non-spatial memory after selective prefrontal lesions in monkeys. Brain Research, 143, 313323.

Newman, J. D., \& Lindsley, D. F. (1976). Single unit analysis of auditory processing in squirrel monkey frontal cortex. Experimental Brain Research, 25, 169-181.

NinOKURA, Y., MUSHIAKE, H., \& TANJI, J. (2003). Representation of the temporal order of visual objects in the primate lateral prefrontal cortex. Journal of Neurophysiology, 89, 2868-2873.

Ó ScalaidHe, S. P., WiLson, F. A.W., \& GoldMAN-RaKic, P. S. (1997). 
Areal segregation of face-processing neurons in prefrontal cortex. Science, 278, 1135-1138.

Ó SCAlAIDHE, S. P., WilsON, F. A. W., \& Goldman-RaKic, P. S. (1999). Face-selective neurons during passive viewing and working memory performance of rhesus monkeys: Evidence for intrinsic specialization of neuronal coding. Cerebral Cortex, 9, 459-475.

Pandya, D. N., Hallett, M., \& KMukherJee, S. K. (1969). Intra- and interhemispheric connections of the neocortical auditory system in the rhesus monkey. Brain Research, 14, 49-65.

PANDYA, D. N., \& KuYPERS, H. G. (1969). Cortico-cortical connections in the rhesus monkey. Brain Research, 13, 13-36.

Passingham, R. [E.] (1975). Delayed matching after selective prefrontal lesions in monkeys (Macaca mulatta). Brain Research, 92 , 89-102.

PASSINGHAM, R. E., Toni, I., \& Rushworth, M. F. (2000). Specialisation within the prefrontal cortex: The ventral prefrontal cortex and associative learning. Experimental Brain Research, 133, 103-113.

Paxinos, G., Huang, X., \& Toga, A. W. (2000). The rhesus monkey brain. San Diego: Academic Press.

Petrides, M. (1986). The effect of periarcuate lesions in the monkey on the performance of symmetrically and asymmetrically reinforced visual and auditory go, no-go tasks. Journal of Neuroscience, 6, 20542063.

Petrides, M., Alivisatos, B., \& Frey, S. (2002). Differential activation of the human orbital, mid-ventrolateral, and mid-dorsolateral prefrontal cortex during the processing of visual stimuli. Proceedings of the National Academy of Sciences, 99, 5649-5654.

Petrides, M., \& Pandya, D. N. (1988). Association fiber pathways to the frontal cortex from the superior temporal region in the rhesus monkey. Journal of Comparative Neurology, 273, 52-66.

Pigarev, I. N., RizzolatTi, G., \& Scandolara, C. (1979). Neurons responding to visual stimuli in the frontal lobe of macaque monkeys. Neuroscience Letters, 12, 207-212.

Preuss, T. M., \& GoldMAN-RAKIC, P. S. (1989). Connections of the ventral granular frontal cortex of macaques with perisylvian premotor and somatosensory areas: Anatomical evidence for somatic representation in primate frontal association cortex. Journal of Comparative Neurology, 282, 293-316.

Preuss, T. M., \& GoLDMAN-RAKIC, P. S. (1991). Myelo- and cytoarchitecture of the granular frontal cortex and surrounding regions in the strepsirhine primate Galago and the anthropoid primate Macaca. Journal of Comparative Neurology, 310, 429-474.

PuCE, A., Allison, T., \& McCarthy, G. (1999). Electrophysiological studies of human face perception: III. Effects of top-down processing on face-specific potentials. Cerebral Cortex, 9, 445-458.

Rainer, G., AsaAd, W. F., \& Miller, E. K. (1998). Memory fields of neurons in the primate prefrontal cortex. Proceedings of the National Academy of Sciences, 95, 15008-15013.

RAJKOWSKa, G., \& GoLDMAN-RAKIC, P. S. (1995). Cytoarchitectonic definition of prefrontal areas in the normal human cortex: I. Remapping of areas 9 and 46 using quantitative criteria. Cerebral Cortex, $\mathbf{5}$, 307-322.

Rama, P., Poremba, A., Sala, J. B., Yee, L., Malloy, M., Mishkin, M., \& Courtney, S. M. (2004). Dissociable functional cortical topographies for working memory maintenance of voice identity and location. Cerebral Cortex, 14, 768-780.

RaO, S. C., Rainer, G., \& Miller, E. K. (1997). Integration of what and where in the primate prefrontal cortex. Science, 276, 821-824.

Rauschecker, J. P., \& Tian, B. (2000). Mechanisms and streams for processing of "what" and "where" in auditory cortex. Proceedings of the National Academy of Sciences, 97, 11800-11806.

Romanski, L. M., Averbeck, B. B., \& Diltz, M. (2005). Neural representation of vocalizations in the primate ventrolateral prefrontal cortex. Journal of Neurophysiology, 93, 734-747.

Romanski, L. M., BATES, J. F., \& GoLDMAN-RAKIC, P. S. (1999). Auditory belt and parabelt projections to the prefrontal cortex in the rhesus monkey. Journal of Comparative Neurology, 403, 141-157.
Romanski, L. M., \& Goldman-RAKIC, P. S. (2002). An auditory domain in primate prefrontal cortex. Nature Neuroscience, 5, 15-16.

Romanski, L. M., Tian, B., Fritz, J., MishKin, M., GoldmaN-RaKiC, P. S., \& RAuscheckeR, J. P. (1999). Dual streams of auditory afferents target multiple domains in the primate prefrontal cortex. Nature Neuroscience, 2, 1131-1136.

Romo, R., Brody, C. D., Hernandez, A., \& Lemus, L. (1999). Neuronal correlates of parametric working memory in the prefrontal cortex. Nature, 399, 470-473.

Rosenkilde, C. E., Bauer, R. H., \& Fuster, J. M. (1981). Single cell activity in ventral prefrontal cortex of behaving monkeys. Brain Research, 209, 375-394.

RUShworTh, M. F., Nixon, P. D., EAcott, M. J., \& PAssingham, R. E. (1997). Ventral prefrontal cortex is not essential for working memory. Journal of Neuroscience, 17, 4829-4838.

RUSSO, G. S., \& BRUCE, C. J. (1989). Auditory receptive fields of neurons in frontal cortex of rhesus monkey shift with direction of gaze. Society for Neuroscience Abstracts, 15, 1204.

Scott, S. K., Blank, C. C., Rosen, S., \& Wise, R. J. (2000). Identification of a pathway for intelligible speech in the left temporal lobe. Brain, 12, 2400-2406.

Selemon, L. D., \& Goldman-RaKic, P. S. (1988). Common cortical and subcortical targets of the dorsolateral prefrontal and posterior parietal cortices in the rhesus monkey: Evidence for a distributed neural network subserving spatially guided behavior. Journal of Neuroscience, 8, 4049-4068.

SMITH, E. E., \& JoNIDES, J. (1999). Storage and executive processes in the frontal lobes. Science, 283, 1657-1661.

SuzuKi, H., \& Azuma, M. (1983). Topographic studies on visual neurons in the dorsolateral prefrontal cortex of the monkey. Experimental Brain Research, 53, 47-58.

TANILA, H., CARLSON, S., LINNANKOSKI, I., \& KaHILA, H. (1993). Regional distribution of functions in dorsolateral prefrontal cortex of the monkey. Behavioural Brain Research, 53, 63-71.

Tanila, H., Carlson, S., Linnankoski, I., Lindroos, F., \& Kahila, H. (1992). Functional properties of dorsolateral prefrontal cortical neurons in awake monkey. Behavioural Brain Research, 47, 169-180.

Tian, B., Reser, D., Durham, A., Kustov, A., \& RauscheCKer, J. P. (2001). Functional specialization in rhesus monkey auditory cortex. Science, 292, 290-293.

UNGERLEIDER, L. G., \& MishKIN, M. (1982). Two cortical visual systems. In D. J. Ingle, M. A. Goodale, \& R. J. W. Mansfield (Eds.), Analysis of visual behavior (pp. 549-586). Cambridge, MA: MIT Press.

Vaadia, E., Benson, D. A., Hienz, R. D., \& Goldstein, M. H., JR. (1986). Unit study of monkey frontal cortex: Active localization of auditory and of visual stimuli. Journal of Neurophysiology, 56, 934952.

Wallis, J. D., \& Miller, E. K. (2003). Neuronal activity in primate dorsolateral and orbital prefrontal cortex during performance of a reward preference task. European Journal of Neuroscience, 18, 20692081.

Webster, M. J., Bachevalier, J., \& Ungerleider, L. G. (1994). Connections of inferior temporal areas TEO and TE with parietal and frontal cortex in macaque monkeys. Cerebral Cortex, 4, 470-483.

Wilson, F. A.W., Ó Scalaidhe, S. P., \& Goldman-RaKic, P. S. (1993). Dissociation of object and spatial processing domains in primate prefrontal cortex. Science, 260, 1955-1958.

Wollberg, Z., \& SEla, J. (1980). Frontal cortex of the awake squirrel monkey: Responses of single cells to visual and auditory stimuli. Brain Research, 198, 216-220.

Zatorre, R. J., BoUfFard, M., \& Belin, P. (2004). Sensitivity to auditory object features in human temporal neocortex. Journal of Neuroscience, 24, 3637-3642.

(Manuscript received September 16, 2004; revision accepted for publication December 10, 2004.) 